\title{
Spectroscopic evaluation of carbohydrate levels in cell line treated with red microalgal polysaccharides
}

\author{
Vitaly Erukhimovitch*, Marina Talyshinsky, Yelena Souprun and Mahmoud Huleihel \\ The Institute for Applied Biosciences, Ben-Gurion University of the Negev, Beer-Sheva, Israel
}

\begin{abstract}
Sulfated polysaccharides obtained from red microalgae proved to be as potent antiviral agents against various viruses. The huge molecular weight of these polysaccharides contributed much to the difficulty in explaining and understanding the mechanism of their activity against internal steps in the replication cycle of these viruses. In the present study we used microscopic Fourier-Transform Infrared Spectroscopy (FTIR) to investigate: (a) possible penetration of these polysaccharides into the treated cells, (b) effect of the polysaccharides treatment on some metabolic changes in these cells. Our results show a rapid accumulation of carbohydrates in the treated Vero cells. The carbohydrates level in these cells increases continuously after treatment during the entire experiment time period. In addition, we noted a gradual shift of $\mathrm{PO}_{2}$-ionized symmetric stretching peak of Vero cells to the position found in primary cells as a result of the continuous treatment with the microalgal polysaccharides.
\end{abstract}

\section{Introduction}

Infrared (IR) spectroscopy is well known for its uniqueness as a noninvasive method in identifying vibrational structure of materials. Various biomolecular components of the cell give a characteristic IR spectrum, which is rich in structural and functional aspects [1,2]. One of the most promising applications of Fourier transform infrared (FTIR) spectroscopy is in biomedicine, particularly for detecting and monitoring characteristic changes in molecular compositions and structures that accompany a transformation from a normal to a cancerous state [3-5].

Sulfated polysaccharides obtained from red microalgae are known with their potent antiviral activity against various viruses such as herpes viruses [6] and retroviruses (involved in various animal and human tumors and leukemias) [7]. The high molecular weight of these polysaccharides contributed much to the difficulty in explaining and understanding the mechanism of their activity against internal steps in the replication cycle of these viruses.

In the present study we examined the effect of these polysaccharides on cells in culture using FTIR microscopy.

Our results showed interesting behaviour of the internal levels of carbohydrates in the treated cells. There is a significant increase in carbohydrates level immediately after treatment. Our spectroscopic data indicate also for some metabolic changes of the polysaccharide treated cells (which are considered as cancer cells) to their normal state.

\footnotetext{
*Corresponding author: Dr.Vitaly Erukhimovitch, The Institutes for Biosciences, Ben-Gurion University of the Negev, P.O. Box 653, Beer-Sheva 84105, Israel. Tel.: +972 8 6461999; Fax: +972 8 6472970; E-mail: evitaly@ bgumail.bgu.ac.il.
} 


\section{Materials and methods}

\subsection{Cells}

Monkey kidney (Vero) cells were grown at $37^{\circ} \mathrm{C}$ in RPMI medium supplemented with $10 \%$ new born calf serum (NBCS) and the antibiotics penicillin, streptomycin and neomycin.

Preparation and purification of microalgal polysaccharide. Polysaccharides produced from the red microalga Porphyridium sp. were used in this study. The polysaccharides were collected and purified as previously described [8]. Briefly, these polysaccharides are produced and secreted into the growth medium by the red microalgae. The medium was collected, cells were removed by centrifugation and the supernatant containing the polysaccharides was dialyzed and lyophilized.

Preparation of slides. Since ordinary glass slides exhibit strong absorption in the wavelength range of interest to us, we used zinc sellenide crystals, which are highly transparent to IR radiation. Normal cells from passage 3-5 were picked up from the tissue culture plates after treatment with trypsin $(0.25 \%)$ for $1 \mathrm{~min}$. The cells were pelted by centrifugation at $1000 \mathrm{rpm}$ for $5 \mathrm{~min}$. Each pellet was washed twice with saline and resuspended in $100 \mu \mathrm{l}$ of saline. The number of cells was counted with hematocytometer, and all tested samples were pelted again and resuspended in an appropriate volume of saline to give a concentration of 1000 cells $/ \mu \mathrm{l}$. A drop of $1 \mu \mathrm{l}$ of each sample was placed on a certain area on the sellenide crystal, air dried and examined by FTIR microscopy. The radius of such $1-\mu 1$ drop was about $1 \mathrm{~mm}$.

FTIR spectra. FTIR measurements were performed in transmission mode with a liquid- nitrogencooled MCT detector of FTIR microscope (Bruker IR Scope II) coupled to the FTIR spectrometer (BRUKER EQUINOX model 55/S, OPUS software). The spectra were obtained in the wave number range of $600-4000 \mathrm{~cm}$ in the mid-IR region. A spectrum was taken as an average of 128 scans to increase the signal to noise ratio, and the spectral resolution was at $4 \mathrm{~cm}^{-1}$. The aperture used in this study is 100 micron. We found that this aperture is the best for good signal to noise ratio on one side and limited preferable region on the other side. The spectra were vector normalized after rubber base line correction. For each cell type, we took at least 5 different measurements at various sites.

\section{Results and discussion}

\subsection{IR spectra of vero cells treated with red microalgal polysaccharide}

Vero cells were treated with 100 or $1000 \mu \mathrm{g} / \mathrm{ml}$ of $P s p$ polysaccharide. At various times after treatment the cells were examined by FTIR spectroscopy. Figure 1a shows the general spectra of untreated and treated cells and Fig. 1b shows the spectra of these cells at carbohydrates region in the area $1000-1200 \mathrm{~cm}^{-1}$. Our results demonstrate higher levels of carbohydrates in the treated cells with Psp polysaccharide compared to the untreated cells as confirmed by the peaks at 1023.3, 1053.8, 1122.4 and $1156.6 \mathrm{~cm}^{-1}$. These spectral peaks are attributed to carbohydrates as previously reported [3] and as can be seen from our results presented in Fig. 2 which show the FTIR spectra of Psp polysaccharide. Peaks at positions 1036 and $1163 \mathrm{~cm}^{-1}$ (seen in Fig. 2) seem to be responsible for the increase in peaks 1023 and $1156 \mathrm{~cm}^{-1}$ in the treated cells due to their related positions. 

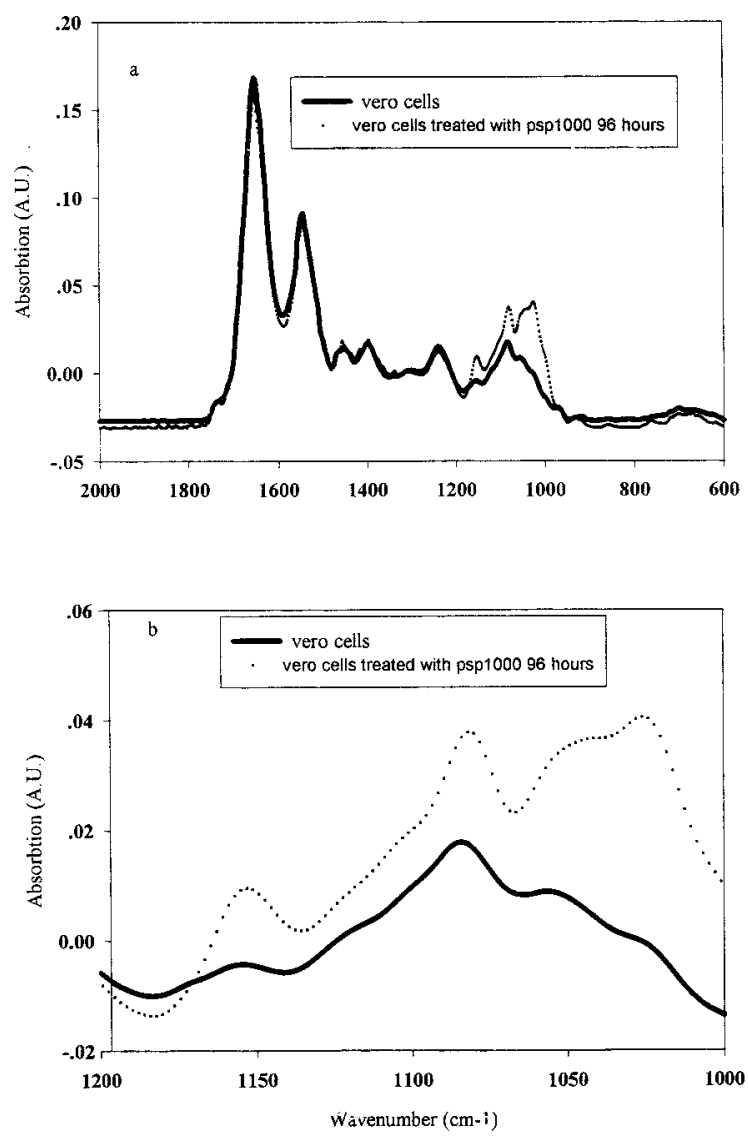

Fig. 1. FTIR spectra of untreated and treated cells with $P s p$ polysaccharide for $96 \mathrm{~h}$. (a) At region $600-2000 \mathrm{~cm}^{-1}$. (b) At region $1000-1200 \mathrm{~cm}^{-1}$.

\subsection{Kinetics of carbohydrate increase in Vero cells treated with polysaccharide}

Our results show a rapid increase in cellular carbohydrate content at $24 \mathrm{~h}$ after treatment, as confirmed by the increase in the absorbance levels of peaks at 1023 and $1156 \mathrm{~cm}^{-1}$ (Figs 3 and 4). It can be seen that carbohydrates continue in their linear increase in the treated cells during the whole tested period of time. In addition, the increase rate of carbohydrates levels was significantly higher in cells treated with $1000 \mu \mathrm{g} / \mathrm{ml}$ of polysaccharide compared to those treated with $100 \mu \mathrm{g} / \mathrm{ml}$ of polysaccharide mainly at the first $24 \mathrm{~h}$ of treatment.

It is important to mention that untreated Vero cells showed a light continuous decrease in carbohydrates level during the tested period of time presumably due to consumption of their carbohydrates for metabolic activities (data not shown).

These results indicate for a possible penetration of the polysaccharide from the medium to the treated cells. It can be concluded also that the $P s p$ polysaccharide solution (used in these experiments) probably contains small fragments of this high molecular weight polysaccharide, due to the difficulty in the penetration of such huge molecules into the cells. 


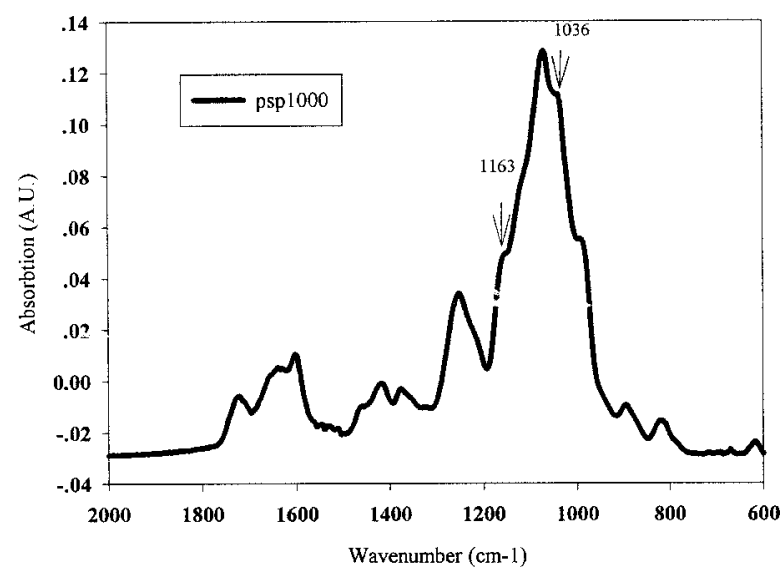

Fig. 2. FTIR spectra of $P s p$ polysaccharide.

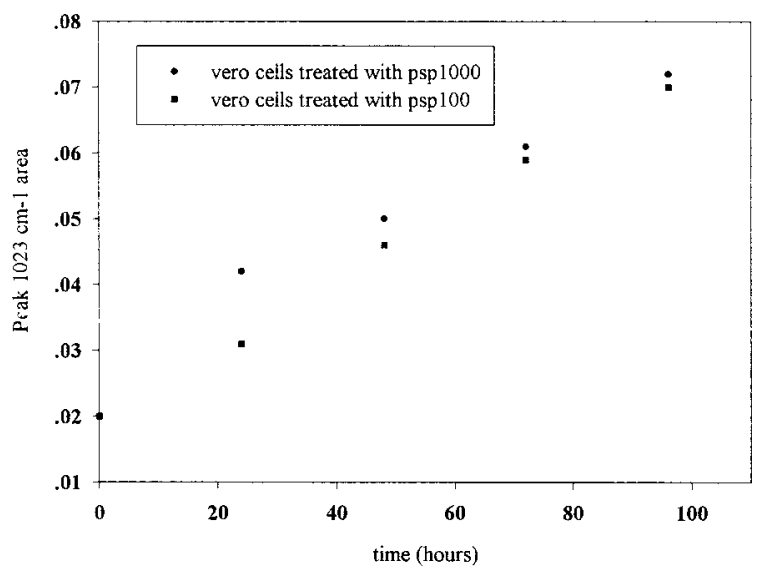

Fig. 3. Effect of Psp polysaccharide on carbohydrate peak level at $1023 \mathrm{~cm}^{-1}$.

\subsection{Effect of Psp polysaccharide on phosphate peak position}

Our previous results [9] showed that the $\mathrm{PO}_{2}^{-}$symmetric stretching vibration of primary cells obtained from various organs of different mamals was at position $\sim 1081 \mathrm{~cm}^{-1}$, cell lines at position $\sim 1084 \mathrm{~cm}^{-1}$ and malignant cells at position $\sim 1087 \mathrm{~cm}^{-1}$.

The results obtained in the present study (Fig. 5) showed a shift in the position of this peak from $1084 \mathrm{~cm}^{-1}$ to $1081 \mathrm{~cm}^{-1}$ during the first $48 \mathrm{~h}$ of treatment of Vero cells with the polysaccharide. These results might point out that treatment of Vero cells, which are cell line, with polysaccharide caused them to behave like primary cells in some of their characteristics. This polysaccharide, at the lower used concentration $(100 \mu \mathrm{g} / \mathrm{ml})$ has no effect on the replication rate of these cells, whereas, in its higher concentration $(1000 \mu \mathrm{g} / \mathrm{ml})$ it slowed down the replication rate of these cells but there were no detectable morphological changes [6]. 


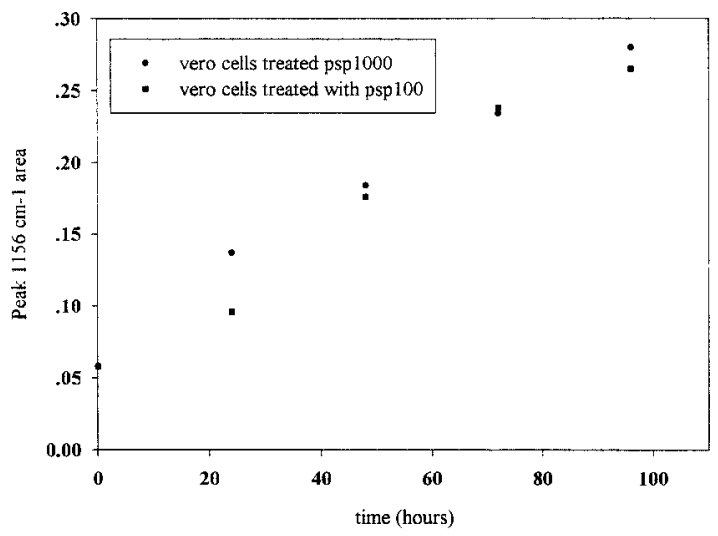

Fig. 4. Effect of Psp polysaccharide on carbohydrate peak level at $1156 \mathrm{~cm}^{-1}$.

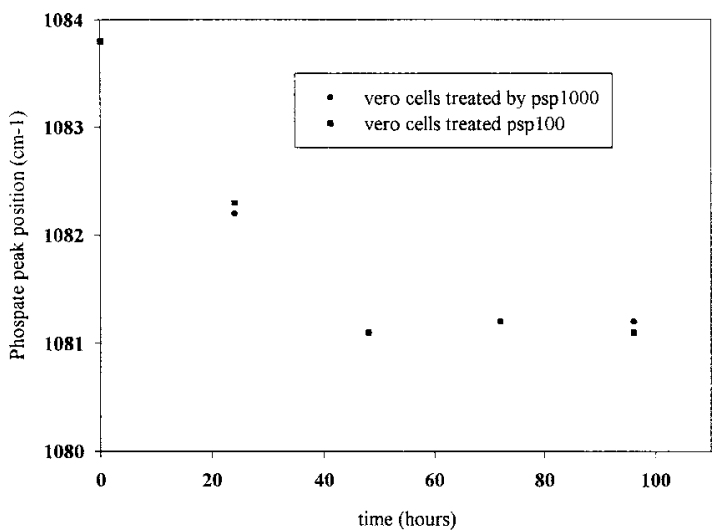

Fig. 5. Effect of $P s p$ polysaccharide on $\mathrm{PO}_{2}^{-}$symmetric stretching vibration peak.

\section{Conclusions}

In the present study we show the ability of FTIR microscopy to detect metabolic changes resulted from treatment of the cells with microalgal polysaccharides. Our spectroscopic results indicate for the penetration of algal polysaccharides into the treated cells.

\section{References}

[1] H. Mantsch and D. Chapman, Infrared Spectroscopy of Biomolecules, John Wiley, NY, 1996, chap. 2, 6-9.

[2] H.P. Wang, H.C. Wang and Y.J. Huang, Sci. Total Environ. 204 (1997), 283-287.

[3] R.K. Dukor, Handbook of Vibrational Spectroscopy, J.M. Chalmers and P.R. Griffiths, eds, John Wiley and Sons, 2001, pp. 3335-3360.

[4] M. Huleihel, V. Erukhimovitch, M. Talyshinsky and M. Karpasas, Spectroscopic characterzition of normal primary and malignant cells transformed by retroviruses, Appl. Spectroscopy 56(5) (2002), 640-645.

[5] B. Rigas, K. LaGuardia, L. Qiao, P.S. Bhandare, T. Caputo and M.A. Cohenford, J. Lab. Clin. Med. 35 (2000), $26-31$.

[6] M. Huleihel, V. Ishanu, J. Tal and S. Arad, J. Appl. Phycol. 13 (2001), 127-134.

[7] M. Huleihel and S. Arad, Anti-Cancer Res. 21(3B) (2001), 2073-2078.

[8] O. Dubinsky, O. Simon, Y. Karamanos, S. Geresh, Z. Barak and S. Arad (Malis), Plant Physiol. Biochem. 30 (1992), 409-414.

[9] V. Erukhimovitch, M. Talyshinsky, Y. Souprun and M. Huleihel, Photochem. Photobiol. (2002), in press. 


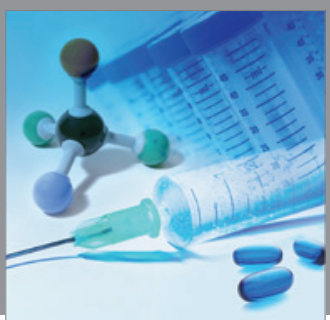

International Journal of

Medicinal Chemistry

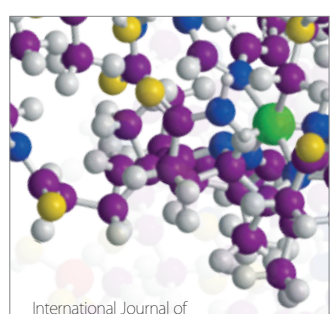

Carbohydrate Chemistry

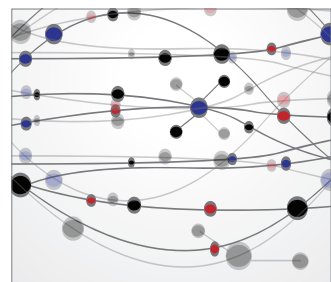

The Scientific World Journal
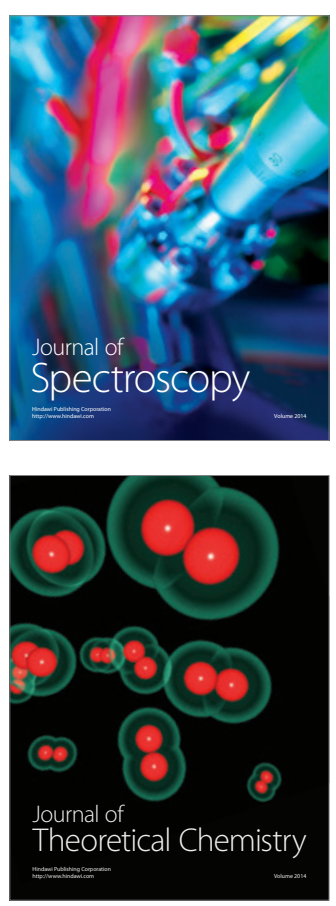
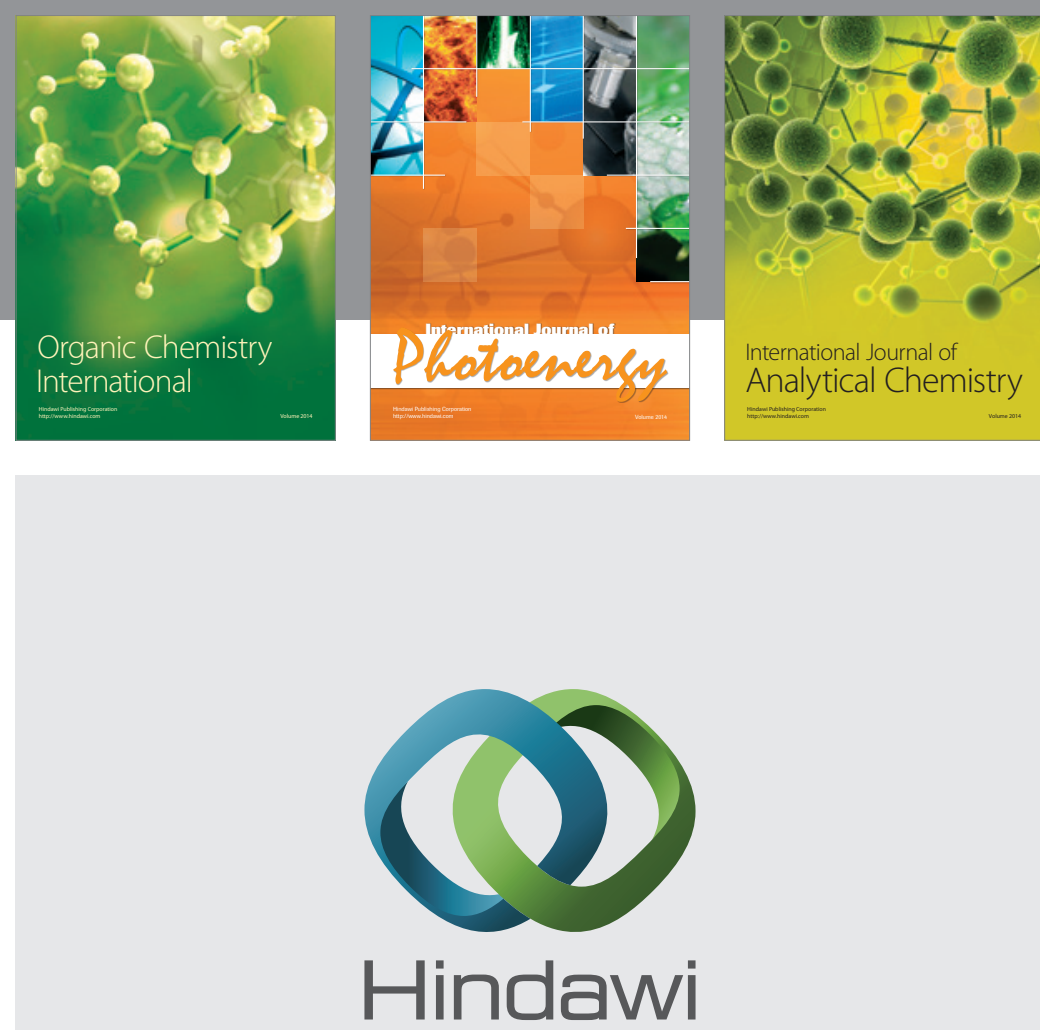

Submit your manuscripts at

http://www.hindawi.com
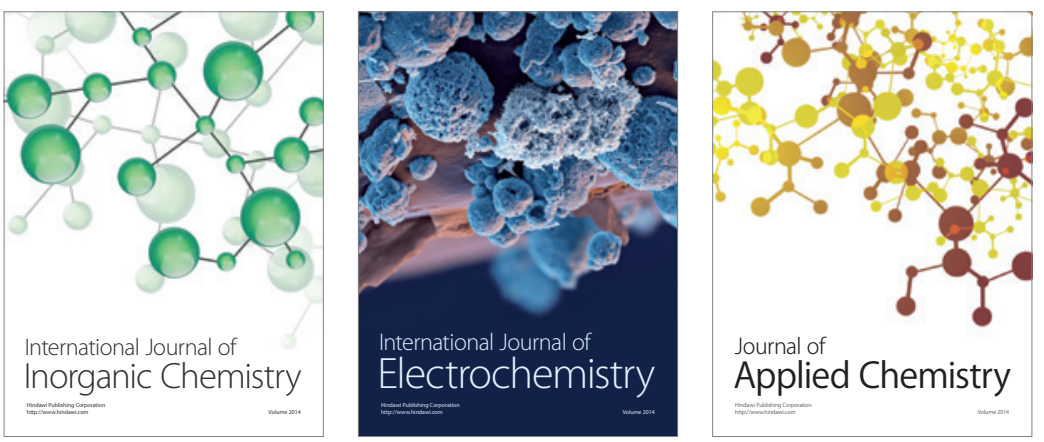

Journal of

Applied Chemistry
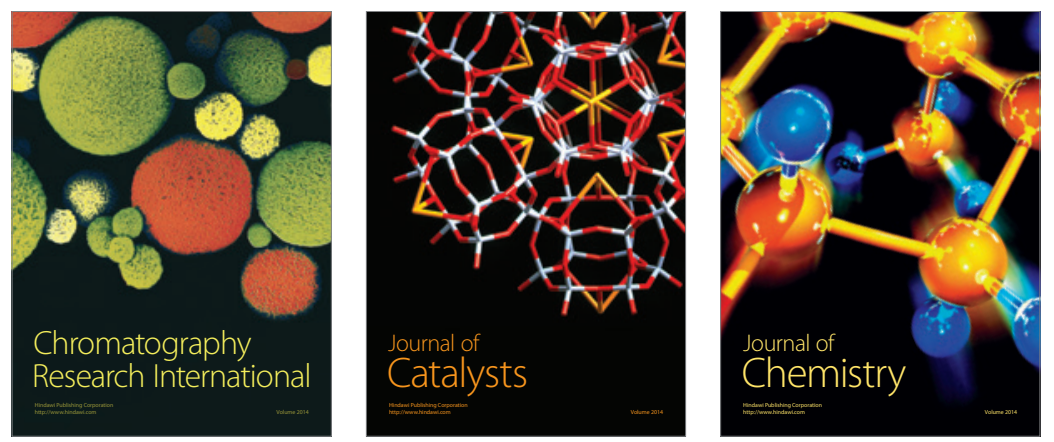
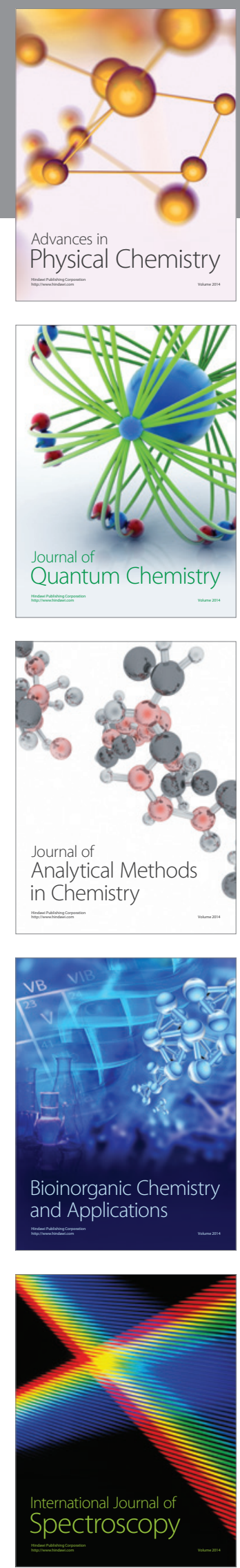